\title{
TEVACS: DECISION SUPPORT SySTEM FOR Evacuation Planning in Taiman ${ }^{a}$
}

\author{
By Anthony F. Han' \\ (Reviewed by the Urban Transportation Division)
}

\begin{abstract}
A microcomputer-based decision support system is developed for transportation network evacuation applications in Taiwan, the Republic of China. Input to the system mainly includes the trip-generation-related atributes, the street network topology and traffic data, the control variables regarding the routing of public transportation vehicles, and the use of traffic control measures. A dynamic network simulation model based on traffic flow theory is used to simulate the vehicles' movement on the street network during the evacuation process. For a given evacuation plan, the network simulation module calculates the estimated network clearance time. The intermediate results of each simulation interval are saved in graphic data files. The planner can use the graphic display module of the system to visually observe the dynamic change of traffic congestion on each link of the network throughout the simulated evacuation process. The system thus provides a convenient tool not only for evaluating different evacuation plans but also for identifying and improving the evacuation bottlenecks on the street network. Application examples of hypothetical cases show that appropriate deployment of public transportation vehicles plus adequate use of traffic control measures can save up to $40 \%$ of the network clearance time during an emergency evacuation.
\end{abstract}

\section{INTRODUCTION}

The transportation evacuation system (TEVACS) is a microcomputer-based system developed to aid an emergency manager in making decisions about evacuation planning in Taiwan, the Republic of China (R.O.C.). Numerous network evacuation models have been developed since the Three Mile accident of March 1979. However, few of the existing models such as the PRC Voorhees' "Evacuation Planning Package" (1982), the DYNEV model developed by the KLD Associates ("The Dynev Model" 1982), the NETVAC1 model developed by Sheffi et al. (1982) at MIT, and the EDSS and TEDSS systems developed by Hobeika et al. (1986) and Hobeika and Hwang (1987) at VPI, are applicable to the situation in Taiwan. Specifically, the automobile is not the dominant mode of road transportation in Taiwan; a significant amount of trips are made by public transportation and privately owned motorcycles. Therefore, network evacuation planning in Taiwan has to consider the following two factors: (1) The need for public transportation as a means of evacuation; and (2) the characteristics of mixed traffic, i.e., the different types of vehicles loaded on to the street network during the evacuation. These factors are generally overlooked in the previous studies of network evacuation models and related decision support systems, making it necessary to develop our own models for applications in Taiwan. The TEV-

\footnotetext{
${ }^{a}$ Presented at the February 5-8, 1989, First International Conference on Applications of Advanced Technologies in Transportation Engineering, San Diego, CA.

${ }^{1}$ Prof. and Chmn., Dept. of Transp. Engrg. and Mgmt., Nat. Chiao Tung Univ., Hsinchu 30049, Taiwan, Republic of China.

Note. Discussion open until April 1, 1991. To extend the closing date one month, a written request must be filed with the ASCE Manager of Journals. The manuscript for this paper was submitted for review and possible publication on October 26, 1989. This paper is part of the Journal of Transportation Engineering, Vol. 116, No. 6, November/December, 1990. CASCE, ISSN 0733-947X/90/0006-0821/ $\$ 1.00$ $+\$ .15$ per page. Paper No. 25250.
} 
ACS is thus developed particularly for transportation network evacuation applications in Taiwan.

\section{SYSTEM StRucture}

The TEVACS executes on an NEC-PC 98XA microcomputer with 640K random access memory (RAM) and color graphics capabilities. The NECPC has a Motorola 80286 microprocessor with an 80287 coprocessor, and gives a high-resolution $(1,120 \times 750)$ display in its color graphics mode. The TEVACS comprises four modules: (1) System control module; (2) data management module; (3) network simulation module; and (4) graphic display module.

Input to the TEVACS mainly includes the following:

1. The trip-generation-related attributes such as the population, number of vehicles, and daily trip-making behavior of the inhabitants in each zone.

2. The street-network-related attributes such as the geographic location, length, width, number of lanes, type of pavement, geometric design, free flow speed, and associated traffic data of each road segment.

3. The control variables of an evacuation plan in terms of the routing of the buses used for public evacuation, the locations of gathering points for public evacuation, and the appropriate use of traffic-control measures such as trafficsignal coordination, one-way systems, reversible lanes, etc.

Besides the aforementioned types of data input, the system also requires data regarding the characteristics of vehicles such as the loading capacity and the passenger car equivalency (PCE) of each type of vehicles.

Based on the input data files as well as a specific evacuation plan, the network simulation module of the TEVACS simulates the vehicles' movement on the street network, and calculates the estimated network clearance time required to complete a certain level, set as $96 \%$ in most cases, of total evacuation.

The major output of the TEVACS system includes the estimate of network clearance time of the given evacuation plan, and a map of the identified traffic bottlenecks associated with the evacuation process. The intermediate results of each simulation interval are saved in graphic data files, allowing the user to visually observe the dynamic change of traffic conditions on each link of the street network.

The TEVACS provides a convenient tool for the user to evaluate different evacuation plans. Through the use of the data-editing module of the system, the user can easily modify and change the control variables as well as the network attributes. After implementing the network simulation function of the system, the user can easily make before-and-after studies with the help of the graphics display functions of the system. In such a way, the TEVACS allows the user to consider a wide range of options regarding the physical expansion of the street network, the routing of buses, and the location of gathering points for public evacuation, as well as the adoption of various traffic-control measures for improvement. Therefore, the TEVACS provides a useful tool to aid an emergency manager or planner in making decisions about evacuation planning. 


\section{NETWOAK SIMULATION}

The network simulation model is the core of the system. The model uses a directed graph representation of the street network with links representing one-way streets (two-way streets are represented by two different links in the model), and nodes representing the intersections of links.

The logic of the network simulation model residing in the TEVACS system is the same as that of the NETVAC1 model developed at MIT (Sheffi et al. 1982). The difference between the two models is that the network simulation model developed here has more capabilities than the NETVAC1 model in terms of: (1) The use of different types of vehicles such as buses, automobiles, motorcycles, and bicycles as the means of evacuation; and (2) the deployment of public evacuation routes and gathering points. The traffic behavior of mixed flow with different types of vehicles has been an important research subject in Taiwan. Based on numerous studies on this subject, the Institute of Traffic and Transportation Research, Ministry of Communications, R.O.C., has compiled a table of PCE values of different types of vehicles under different conditions (see Table 1). These results were adopted in this study to convert the number of vehicles into the number of passenger car units (PCU) before applying conventional traffic flow theories.

The basic structure of the simulation model includes two major logical components: the link process and the node process. At every simulation interval, the link process scans all the links and calculates for each link the number of vehicles that would move from the inlet to the outlet of the link. In doing this, both the traffic-flow behavior of the vehicles in motion, and the space occupied by the vehicles in queue have to be considered. Fig. 1 shows a schematic diagram of the link process.

After the link process scans all the links, the node process scans all the nodes. At every simulation interval, the node process calculates for each node (intersection) how many vehicles should move from one inbound link $i$ to an outbound link $j$. The output data of the link process as indicated by $X, Y$, and $Z$ in Fig. 1 now are used as the input of the node process as shown in Fig. 2. The major steps of the nodes process are described herein.

Calculate the number of inbound vehicles, $V I_{i}$.

TABLE 1. The PCE of Different Types of Vehicles in Taiwan

\begin{tabular}{l|c|c|c|c|c|c|c}
\hline \hline $\begin{array}{c}\text { Condition } \\
(1)\end{array}$ & $\begin{array}{c}\text { Passenger car } \\
(2)\end{array}$ & $\begin{array}{c}\text { Taxi } \\
(3)\end{array}$ & $\begin{array}{c}\text { Pick-up van } \\
(4)\end{array}$ & $\begin{array}{c}\text { Bus } \\
(5)\end{array}$ & $\begin{array}{c}\text { Truck } \\
(6)\end{array}$ & $\begin{array}{c}\text { Motorcycle } \\
(7)\end{array}$ & $\begin{array}{c}\text { Bicycle } \\
(8)\end{array}$ \\
\hline \multicolumn{7}{c}{$($ a) General Highway } \\
\hline Plains & 1.0 & 1.0 & 1.0 & 1.5 & 1.5 & 0.3 & 0.5 \\
Terrains & 1.0 & 1.0 & 1.0 & 2.5 & 2.5 & 0.3 & 1.0 \\
Mountains & 1.5 & 1.5 & 1.5 & 5.0 & 5.0 & 0.6 & 2.0 \\
\hline
\end{tabular}

(b) Highway Section with Ascending Grade

\begin{tabular}{c|l|l|l|l|l|l|l}
\hline $0-3 \%$ & 1.0 & 1.0 & 1.0 & 2.0 & 2.0 & 0.3 & 1.0 \\
$4 \%$ & 1.5 & 1.5 & 1.5 & 2.5 & 2.5 & 0.6 & 1.5 \\
$5 \%$ & 2.0 & 2.0 & 2.0 & 3.0 & 3.0 & 0.9 & 2.0 \\
$6 \%$ & 2.5 & 2.5 & 2.5 & 4.0 & 4.0 & 1.2 & 3.0 \\
$7 \%$ & 3.5 & 3.5 & 3.5 & 8.0 & 8.0 & 1.8 & 6.0 \\
\hline
\end{tabular}




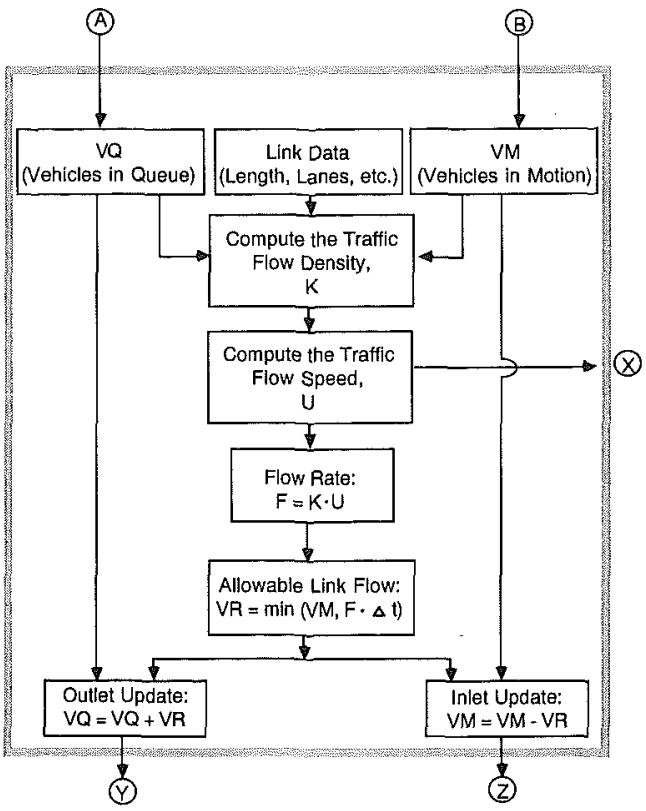

FIG. 1. Schematic Diagram of Link Process

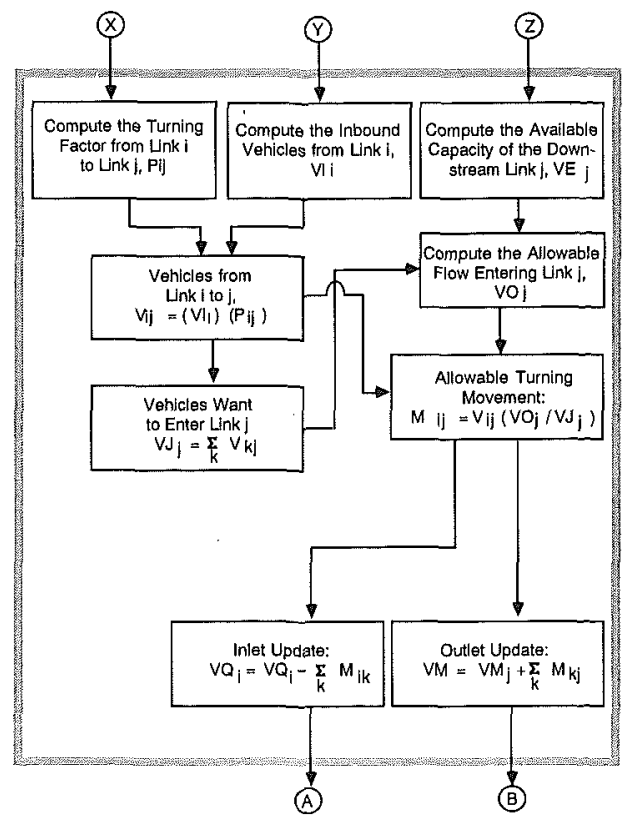

FIG. 2. Schematic Diagram of Node Process 
where $V Q_{i}=$ the number of vehicles leaving link $i$; and $A C_{i}=$ the approach of link $i$ with respect to the intersection node being scanned.

Determine the turning factor, $P_{i j}$.

For private vehicles

$$
P_{i j}=\frac{P F_{i j} \times U_{j}}{\sum_{k} P F_{i k} \times U_{k}}
$$

where $P F_{i j}=$ a preference factor of turning movement from link $i$ to link $j ; U_{j}=$ the flow speed of link $j$; and $k$ represents one outbound link ( $k \neq$ $i$ ). Note that Eq. 2 represents that the turning movement of traffic at the intersection depends on the traffic condition (in terms of the flow speed) of its outbound links.

For those public vehicles that are assigned to specific routes:

$P_{i j}=\left\{\begin{array}{l}1, \text { if link } j \text { is on the assigned route } \\ \text { associated with link } i \\ 0, \text { otherwise }\end{array}\right.$

Calculate the allowable number of vehicles entering the outbound link $j$, $V O_{j}$.

$V O_{j}=\min \left(V J_{j} S_{j} \times \Delta t, V E_{j}\right)$

where $V J_{j}=$ the total number of vehicles which want to enter the outbound link $j ; S_{j}=$ the rate of saturation flow of link $j ; \Delta t=$ the length of the simulation interval; and $V E_{j}=$ the available space (in PCU) of link $j$.

Determine the allowable number of turning vehicles from link $i$ to $j, M_{i j}$.

$M_{i j}=V_{i j}\left(\frac{V O_{j}}{V J_{j}}\right)$

where $V_{i j}=\left(V I_{i}\right)\left(P_{i j}\right)$ is the number of vehicles that want to move from link $i$ to $j$.

A linear speed-density relationship, i.e., the Greenshield model, is used in the network simulation module of the TEVACS system. The simulation module can be modified to include any other traffic-flow models. The specific model used, however, is not going to affect much the results since all traffic-flow models exhibit similar behavior for very heavy traffic, and the linear model is the simplest to use.

\section{Example Results and Analysis}

Two examples of hypothetical networks were used to analyze the performance of the TEVACS system. Figs. 3 and 4 show the graph representation of the two hypotehtical networks, respectively. In both networks the following parameters are assumed:

- Link length $=500 \mathrm{~m}$.

- Number of lanes $=3$. 


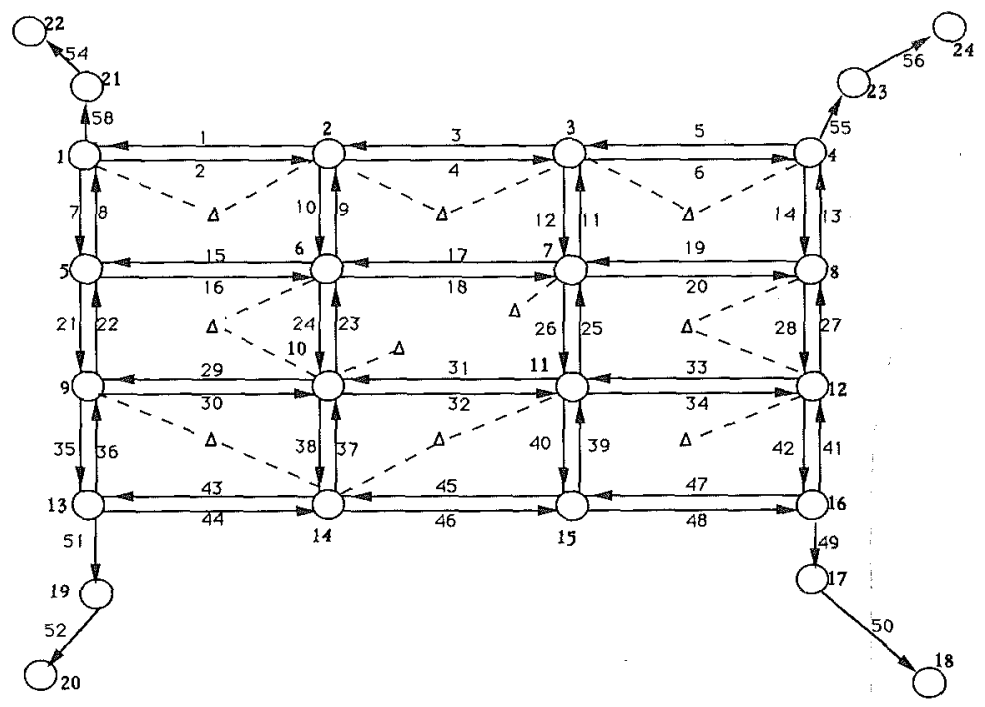

FIG. 3. Hypothetical Network A

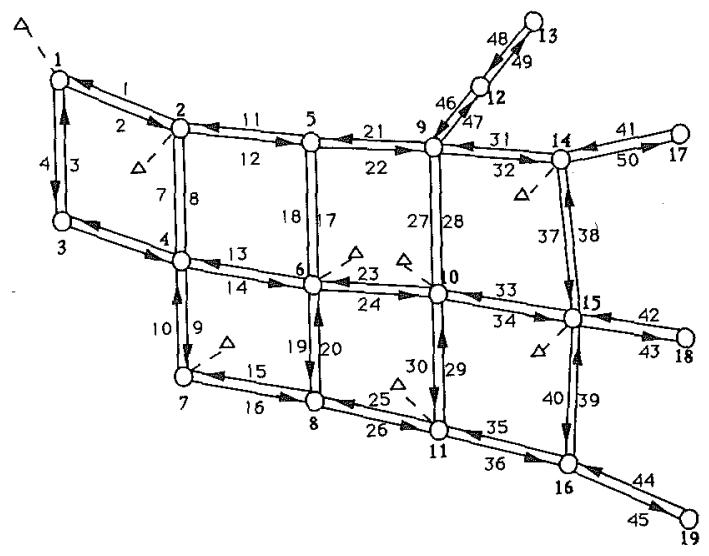

FIG. 4. Hypothetical Network $B$

- Capacity $=1,500 \mathrm{pcu} /$ lane.

- Free flow speed $=50 \mathrm{~km} / \mathrm{h}$.

- Jam density $=200 \mathrm{pcu} / \mathrm{km}$.

Other characteristics of the two networks are summarized in Table 2.

Network A was used primarily for sensitivity analysis, focusing on three factors: the length of simulation interval, the loading time of public vehicles, and the traffic-flow model used in the network simulation. For the base case, the simulation interval and the loading time were set as 30 and $120 \mathrm{sec}$ respectively; and the Greenshield model, which specifies a linear speed-den- 
TABLE 2. Summary of Two Examples

\begin{tabular}{l|c|c}
\hline \multicolumn{1}{c|}{$\begin{array}{c}\text { Data item } \\
\text { (1) }\end{array}$} & $\begin{array}{c}\text { Example A } \\
\text { (2) }\end{array}$ & $\begin{array}{c}\text { Example B } \\
(3)\end{array}$ \\
\hline Number of links & 56 & 50 \\
Number of nodes & 24 & 19 \\
Number of zones & 10 & 9 \\
Private vehicles (PCU) & 5,000 & 4,500 \\
Public vehicles (PCU) & 2,000 & 3,000 \\
Number of public evacuation routes & 4 & 6 \\
Loading time of public vehicles (sec) & 150 & 180 \\
\hline
\end{tabular}

sity relationship, was used. The evacuation time, defined as the network clearance time at $96 \%$ evacuation level, of the base case was estimated as $32 \mathrm{~min}$ and $30 \mathrm{sec}$. The estimates of the evacuation time under different situations are given in Table 3 . The results are quite robust with respect to the changes in the three factors tested. Therefore, different judgments made

TABLE 3. Results of Sensitivity Analysis

\begin{tabular}{|c|c|c|c|}
\hline $\begin{array}{l}\text { Factor } \\
(1)\end{array}$ & $\begin{array}{c}\text { Tested } \\
\text { conditions } \\
(2)\end{array}$ & $\begin{array}{c}\text { Estimates of } \\
\text { evacuation time } \\
\text { (3) }\end{array}$ & $\begin{array}{c}\text { Percentage } \\
\text { difference } \\
(4)\end{array}$ \\
\hline $\begin{array}{l}\text { Length of simulation } \\
\text { interval }\end{array}$ & $\begin{array}{l}10 \mathrm{sec} \\
20 \mathrm{sec} \\
30 \mathrm{sec} \\
40 \mathrm{sec} \\
50 \mathrm{sec} \\
60 \mathrm{sec}\end{array}$ & $\begin{array}{l}32 \mathrm{~min} 20 \mathrm{sec} \\
32 \mathrm{~min} 20 \mathrm{sec} \\
32 \mathrm{~min} 30 \mathrm{sec} \\
34 \mathrm{~min} \\
34 \mathrm{~min} 10 \mathrm{sec} \\
32 \mathrm{~min}\end{array}$ & $\begin{array}{r}-1.0 \% \\
-1.0 \% \\
-{ }^{2} \\
4.6 \% \\
5.1 \% \\
-1.5 \%\end{array}$ \\
\hline $\begin{array}{l}\text { Loading time of } \\
\text { public vehicles }\end{array}$ & $\begin{array}{r}60 \mathrm{sec} \\
120 \mathrm{sec} \\
150 \mathrm{sec} \\
180 \mathrm{sec}\end{array}$ & $\begin{array}{l}32 \mathrm{~min} \\
32 \mathrm{~min} 30 \mathrm{sec} \\
32 \mathrm{~min} 30 \mathrm{sec} \\
32 \mathrm{~min} 30 \mathrm{sec}\end{array}$ & $\begin{array}{c}-1.5 \% \\
0 \% \\
-{ }^{a} \\
0 \%\end{array}$ \\
\hline Traffic flow model & $\begin{array}{l}\text { Greenshield } \\
\text { Greenberg } \\
\text { Underwood } \\
\text { Bell-Shape }\end{array}$ & $\begin{array}{l}32 \mathrm{~min} 30 \mathrm{sec} \\
34 \mathrm{~min} 30 \mathrm{sec} \\
32 \mathrm{~min} \\
32 \mathrm{~min} 30 \mathrm{sec}\end{array}$ & $\begin{array}{l}-\overline{6} \\
6.1 \% \\
-1.5 \% \\
0 \%\end{array}$ \\
\hline
\end{tabular}

${ }^{\mathrm{a}}$ Not applicable for the base case.

TABLE 4. Six Assigned Evacuation Routes

\begin{tabular}{c|c|c|c}
\hline \hline $\begin{array}{c}\text { Route number } \\
(1)\end{array}$ & $\begin{array}{c}\text { Traffic zone } \\
(2)\end{array}$ & $\begin{array}{c}\text { Source node } \\
(3)\end{array}$ & \multicolumn{1}{|c}{$\begin{array}{c}\text { Assigned route } \\
(4)\end{array}$} \\
\hline 1 & 1 & 1 & $2-12-22-47-49$ \\
2 & 2 & 2 & $12-22-47-29$ \\
3 & 3 & 4 & $9-12-26-36-45$ \\
4 & 5 & 6 & $24-34-43$ \\
5 & 7 & 11 & $36-45$ \\
6 & 8 & 15 & 43 \\
\hline
\end{tabular}




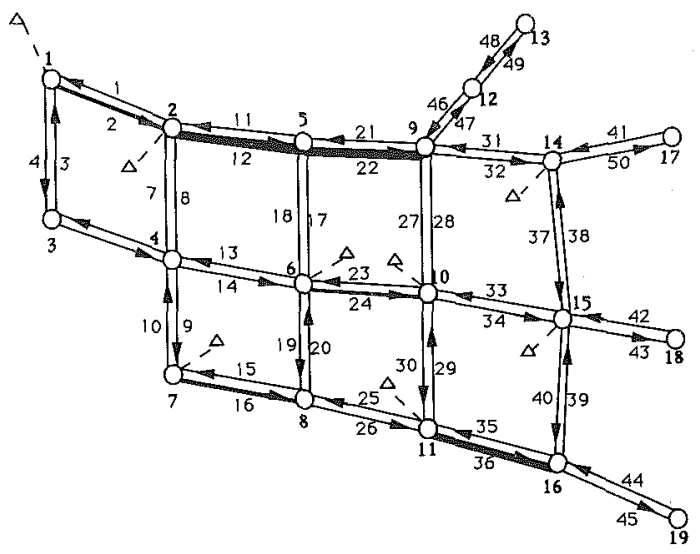

FIG. 5. Display of Evacuation Bottlenecks

by the system operator would not affect the outcome of the network simulation much.

As the second example application, the network B (Fig. 4) was used to test how the system can be used to improve an evacuation plan. It was assumed that there were 500 private vehicles (in PCU) in each traffic zone, and the gathering points for public evacuation were located at six different zones. The assigned routes for public evacuation are given in Table 4 .

The estimated evacuation time of the base case was $47 \mathrm{~min}$. With the help of TEVACS system, the six most congested links, on which the traffic density is more than half of the jam density for more than $40 \%$ of the time, were identified: links $2,12,16,22,24$, and 36 . These links are shown in Fig. 5 with bold lines. This information was used to help design alternative evacuation plans.

The following four alternative plans were designed to reduce the evacuation time:

1. Alternative I-Rearrange the six public evacuation routes.

2. Alternative II-Change the pretimed traffic signal control at 11 intersections to adaptive control.

3. Alternative III-Use reversible traffic lanes, i.e., change the $3 / 3$ lane distribution to $5 / 1$ lane distribution, to give two more lanes for evacuation on 11 two-way links.

4. Alternative IV-Combine all the measures considered in alternatives I through III.

Results of these alternative plans are given in Table 5. Alternative I showed little improvement mainly because the tested network is rather small and thus allows little room for rearranging the public evacuation routes. Both alternatives II and III showed approximately $15 \%$ reduction in the evacuation time. This implies that appropriate use of traffic control measures can effectively improve the efficiency of evacuation. Combining measures taken in alternatives I-III, alternative IV gave the most significant improvement, 
TABLE 5. Evaluation of Alternative Plans

\begin{tabular}{c|c|c|c}
\hline $\begin{array}{c}\text { Alternative } \\
\text { (1) }\end{array}$ & \multicolumn{1}{c|}{$\begin{array}{c}\text { Measures taken } \\
(2)\end{array}$} & $\begin{array}{c}\text { Estimates of } \\
\text { evacuation time } \\
(3)\end{array}$ & $\begin{array}{c}\text { Percentage } \\
\text { improvement (\%) } \\
(4)\end{array}$ \\
\hline $\begin{array}{c}\text { Base case } \\
\text { I }\end{array}$ & $\begin{array}{c}\text { Rearrange evacuation } \\
\text { routes } \\
\text { Improve traffic signal } \\
\text { control }\end{array}$ & $\begin{array}{l}47 \mathrm{~min} \\
46 \mathrm{~min} 30 \mathrm{sec}\end{array}$ & 1.1 \\
II & $\begin{array}{l}\text { Use reversible lanes } \\
\text { Combine I, II, and III }\end{array}$ & $\begin{array}{l}40 \mathrm{~min} \mathrm{30} \mathrm{sec} \\
28 \mathrm{~min}\end{array}$ & 17.0 \\
III & & 40.4 \\
\hline
\end{tabular}

${ }^{a}$ Not applicable to the base case.

with about $40 \%$ reduction in the evacuation time.

Note that the effect of alternative IV $(40 \%)$ is even higher than the sum of individual effects of the other three alternatives. This can be explained as follows. Alternative II was focused on improvement at the intersections, The expanded intersection capacity, however, can not be fully utilized when its outbound links are seriously congested. Similarly, the expanded link capacity as considered in alternative III might not be effectively used if the downstream intersection was blocked. Therefore, only when both the links and the nodes are considered for traffic improvement as in alternative IV, can the evacuation bottlenecks be effectively alleviated.

\section{Conclusions}

The TEVACS is a microcomputer-based decision support system developed for transportation evacuation planning applications in Taiwan, R.O.C. The TEVACS comprises four modules and executes on an NEC-PC 98XA microcomputer with 640K RAM and color-graphics capabilities. The core of the system is the network simulation model that is an enhanced version of the NETVAC1 model with added capabilities to simulate the flow of different types of vehicles as well as the flow of vehicles used for public evacuation.

The TEVACS is currently applied to estimate evacuation times and to develop effective evacuation plans for the emergency planning zones (EPZ) of three nuclear power plants in Taiwan, R.O.C. For practical applications, the system takes about 3 to $5 \mathrm{~min}$ to simulate the evacuation of 3,000 to 4,200 vehicles (in PCU) on a network with 252 links and 138 nodes. It seems that the TEVACS does provide an inexpensive and effective tool to aid an emergency manager in making decisions about evacuation planning as well as operations.

\section{ACKNOWLEDGMENT}

This research was partially supported by the Atomic Energy Council, the Executive Yuan of the Republic of China. 


\section{Appendix. References}

"The DYNEV model: An effective tool for developing evacuation plans," (1982) paper presented at the 61 st Annual TRB Meeting, KLD Associates, Inc., Washington, D.C.

"Evacuation Planning Package," (1982) paper presented at the 61st Annual TRB Meeting, PRC Voorhees, Washington, D.C.

Hobeika, A. G., and Hwang, K. P. (1986). "A decision support system for evacuation planning and operation in emergency management," paper presented at the 2nd European Simulation Congress, Society for Computer Simulating, Antwerp, Belgium.

Hobeika, A. G., Hwang, K. P. and Han, L. D. (1984). "TEDSS: A transportation evacuation decision support system." Research Paper, Dept. of Civ. Engrg., Virginia Polytechnic Inst. and State Univ., Blacksburg, Va.

Sheffi, Y., Mahmassani, H., and Powell, W. B. (1982). "A Transportation Network Evacuation model." Transp. Res., 16A(3), 209-218. 